Research Article

\title{
Upper respiratory tract infection: drug utilization study
}

\author{
Harish Naik $^{1}$, Ashwini Kolur ${ }^{2}$
}

\begin{abstract}
${ }^{1}$ Department of Pharmacology, Kanachur Institute of Medical Sciences, Deralakatte, Mangalore, Karnataka, India ${ }^{2}$ Department of Pathology, Karwar Institute of Medical Sciences, Karwar, Karnataka, India
\end{abstract}

Received: 26 July 2016

Accepted: 30 July 2016

\section{*Correspondence to:}

Dr. Harish Naik,

Email: harishhnaik@gmail.com

Copyright: () the author(s), publisher and licensee Medip Academy. This is an openaccess article distributed under the terms of the Creative Commons Attribution NonCommercial License, which permits unrestricted noncommercial use, distribution, and reproduction in any medium, provided the original work is properly cited.

\begin{abstract}
Background: One of the most common causes of visit to physician is upper respiratory tract infections (URTI). This infection is often considered to be of little value from a stand point of mortality but this infection is responsible for limited activity and absence from work and school in the general population of nation mainly in a developing country like India, when compared it with other infections.

Methods: This study was conducted in Krishna Institute of Medical Sciences, Karad, India to see the prescription pattern of URTI patients in medicine department. It was a retrospective study record based, observational study and the data were collected from the medical record room.

Results: Out of 212 patients, $53.30 \%$ were of URTI, $31.60 \%$ were sinusitis, pharyngitis and CSOM accounted for $11.79 \%$ and $3.30 \%$ respectively. Female accounted for $62.26 \%$ and male for $37.73 \%$ of total cases. In 8 cases culture and sensitivity was done and all were sterile. Only in 8 cases antimicrobial agents were not prescribed.

Conclusions: Azithromycin was the most commonly used antimicrobial, followed by ceftriaxone. Apart from antibiotics the most frequently prescribed class was antihistamines followed by expectorants and bronchodilators. Paracetamol was the preferred antipyretic. Acid reducing agents were prescribed in $84.82 \%$ of Patients, might be used to check the acidity caused by antibiotics. The use of generic medicines should be promoted.
\end{abstract}

Keywords: Drug utilization, Upper respiratory tract infections, Antihistamines, Bronchodialotors, Antibiotics

\section{INTRODUCTION}

One of the most common cause of visit to physician is Upper respiratory tract infections (URTI). ${ }^{1} \quad$ This infections are often considered to be of little value from a stand point of mortality but this infection is responsible for limited activity and absence from work and school in the general population of nation mainly in a developing country like India, when compared it with other infections. ${ }^{2}$ URTI are commonly caused by the viruses, common viruses which are responsible are rhinovirus, parainfluenza virus, respiratory syncytial virus, influenza virus, coronavirus, coxsackievirus, adenovirus, coxsackievirus. ${ }^{3}$ URTI is an illnesses caused by an acute infection which affects the upper respiratory tract including the nose, sinuses, pharynx or larynx and causes common cold, sinusitis, otitis media, tonsillitis, pharyngitis, laryngitis. ${ }^{4}$

As mentioned above, viruses are the most common causes of URTI and thus it requires only symptomatic treatment. To thin the respiratory secretions, it is usually advised to consume plenty of fluids, especially warm fluids, it will not only help in thinning the secretions but also have some soothing effect on the throat. ${ }^{5}$ Large number of over-the-counter (OTC) agents are available in the market in various combinations, none of them have found to be highly effective. ${ }^{6}$ Group of drugs usually preferred are nonsteroidal anti-inflammatory drugs (NSAIDs) are given for providing symptomatic relief 
from fever, headache, and malaise, expectorant and antitussives for cough or sore throat, decongestants and antihistamines for runny or stuffy nose. ${ }^{7}$

Many studies suggest that, the antibiotics are not required, but almost $75 \%$ of adults with URTIs are given antibiotics by their consulting doctor. ${ }^{8}$ The decision to prescribe antibiotics is intricate and involves number of factors. Apart from clinical factors, others like patient, provider and community characteristics, regulatory practices, cultural influences do play a role. ${ }^{9}$ There are literature which do support the use of antibiotics in URTI, they suggest that active bacterial removal is also necessary in achieving optimal clinical success in URTI. $^{10}$

There are large numbers of highly effective medicines available in the market and even the patients are aware of it and the patients have higher expectation from the health care. So it is very important to know the current prescription trends and if required to make some necessary adjustments that will help in treating the condition in a better way. Prescription monitoring studies could be helpful in identifying the problem associated with prescription and can provide feedback to the general practitioners so as to create consciousness about the irrational use of drugs. ${ }^{11}$ By creating an awareness and preventing the irrational prescription we can increase the effectiveness of the drugs and thus decreasing the morbidity associated with URTI.

The objective of present study is to focus on the trends in the prescription pattern in URTI. This study shows the trends in utilization of different group of medicines in the treatment of URTI.

\section{METHODS}

The present study was carried out in Krishna Institute of Medical Sciences, Karad, India. URTI patients who were admitted during January 2011 to June 2012, in medicine ward of the hospital were included in the study. It was a retrospective study record based, observational study and the data were collected from the Patients case sheets. The information's (prescription pattern and demographic data) collected, were evaluated in detail and data collected were analyzed using Microsoft office excel software.

\section{RESULTS}

A total of 212 case records of the patients were analyzed during the study period. All the case records had all the necessary information like patient's demographic characteristics, diagnosis, drug names, dose route and frequency of intake. Here we are resenting the results of the study. URTI and sinusitis were more common in the females than in the males in the study. Female accounted for $62.26 \%$ and male for $37.73 \%$ of total cases. Nonspecific URTI and sinusitis were more in the age group of 17 to 30 .

Out of the 212 case records, only in 8 cases culture and sensitivity was done culture and they were all totally clean.

Table 1: Distribution of cases according to illness and sex.

\begin{tabular}{|lllllll|}
\hline Illness & Number & $\%$ & Male & \multicolumn{3}{c|}{ Female } \\
\hline URTI(nonspecific URTI) & & & No. & \% & No & \% \\
\hline Sinusitis & 113 & 53.30 & 41 & 19.33 & 72 & 33.96 \\
\hline Pharyngitis & 67 & 31.60 & 27 & 12.73 & 40 & 18.86 \\
\hline CSOM & 25 & 11.79 & 11 & 5.18 & 14 & 6.60 \\
\hline
\end{tabular}

Table 2: Average number of medicines used and out come at the time of discharge.

\begin{tabular}{|llll|}
\hline Illness & Drugs & Improved & Unchanged \\
\hline URTI & 3.57 & 109 & 4 \\
\hline Sinusitis & 3.74 & 67 & 0 \\
\hline Pharyngitis & 3.68 & 25 & 0 \\
\hline CSOM & 4 & 6 & 1 \\
\hline
\end{tabular}

Table 3: Distribution of individual AMAs.

\begin{tabular}{|ll|ll|}
\hline No & Name of the drug & URTI & no of pts \\
\hline Penicillins & & \\
\hline 1 & Amoxicillin & 14 & 6.60 \\
\hline 2 & Amoxicillin + Clavulanic acid & 12 & 5.66 \\
\hline 3 & Ampicillin + Cloxacillin & 1 & 0.47 \\
\hline
\end{tabular}




\begin{tabular}{|c|c|c|c|}
\hline \multicolumn{4}{|c|}{ Cephalosporins } \\
\hline 5 & Cefotaxime & 3 & 1.41 \\
\hline 6 & Cefadroxil & 13 & 6.13 \\
\hline 9 & Cefixime & 26 & 12.26 \\
\hline 11 & Ceftriaxone & 52 & 24.52 \\
\hline 13 & Ceftriaxone + Tazobactam & 1 & 0.47 \\
\hline 14 & Cefpodoxime & 2 & 0.94 \\
\hline \multicolumn{4}{|c|}{ Macrolide } \\
\hline 15 & Azithromycin & 56 & 26.41 \\
\hline \multicolumn{4}{|c|}{ Flouroquinolones } \\
\hline 16 & Ciprofloxacin & 7 & 3.30 \\
\hline 18 & Ofloxacin + Ornidazole & 5 & 2.35 \\
\hline 19 & Levofloxacin & 5 & 2.35 \\
\hline 21 & Norfloxacin & 1 & 0.47 \\
\hline \multicolumn{4}{|c|}{ Tetracycline antibiotic } \\
\hline 22 & Doxycycline & 6 & 2.83 \\
\hline
\end{tabular}

Table 4: Distribution of respiratory drugs.

\begin{tabular}{|c|c|c|c|}
\hline \multirow{2}{*}{ No } & \multirow{2}{*}{ Name of the drug } & \multicolumn{2}{|c|}{ URTI } \\
\hline & & No & $\%$ \\
\hline \multicolumn{4}{|c|}{ Bronchodilators } \\
\hline 1 & Etophylline & 16 & 7.54 \\
\hline 2 & Theophylline & 17 & 8.01 \\
\hline 3 & Doxophylline & 1 & 0.47 \\
\hline 4 & Terbutaline & 30 & 14.15 \\
\hline \multicolumn{4}{|c|}{ Expectorants (Mucolytics) } \\
\hline 5 & Bromhexine & 28 & 13.20 \\
\hline 6 & Guaiphenesin & 30 & 14.15 \\
\hline 7 & Ambroxol & 18 & 8.49 \\
\hline \multicolumn{4}{|c|}{ Antitussives } \\
\hline 8 & Codeine & 2 & 0.94 \\
\hline 10 & Dextromethorphan & 20 & 9.43 \\
\hline \multicolumn{4}{|c|}{ Antihistaminics } \\
\hline 11 & $\begin{array}{l}\text { Chlorpheniramine } \\
\text { maleate }\end{array}$ & 17 & 8.01 \\
\hline 12 & Cetirizine & 48 & 22.64 \\
\hline 13 & Triprolidine & 36 & 16.98 \\
\hline 14 & Levocetirizine & 18 & 8.49 \\
\hline \multicolumn{4}{|c|}{ Nasal decongestants } \\
\hline 15 & Pseudoephedrine & 15 & 7.07 \\
\hline 16 & Phenylephrine & 40 & 18.86 \\
\hline \multicolumn{4}{|c|}{ Leukotriene antagonist } \\
\hline 17 & Montelukast & 14 & 6.60 \\
\hline
\end{tabular}

Table 5: Distribution of antipyretics and acid reducing agents.

\begin{tabular}{|lll|}
\hline Antipyretics & & \\
\hline Paracetamol & 90 & 42.45 \\
\hline Acid reducing agents & & \\
\hline Omeprazole & 106 & 50 \\
\hline Pantoprazole & 66 & 31.13 \\
\hline Ranitidine & 3 & 1.41 \\
\hline
\end{tabular}

\section{DISCUSSION}

As mentioned in the introduction, URTI is responsible for more number of visits to physician than any other infection and also responsible for considerable economic impact. ${ }^{12}$ In general practice, URTI are given empirical treatment and the main intention of the doctor or the healthcare provider is to treat as precisely as possible. Inappropriate use of the antibiotics in URTI can lead to development of resistance among the pathogens which were previously sensitive. ${ }^{13}$

Prescription monitoring studies can provide information to the prescribers and they can look for way to improve their own performance and these studies should become a method of promoting and providing knowledge for the health care provider about the changing trends in URTI, rather than being treated as threat. ${ }^{14}$

The study observed that percentage of females suffering from infection were more than males (Table 1). URTI accounted for $53.30 \%$, sinusitis $31.60 \%$, pharyngitis $11.79 \%$ and CSOM $3.30 \%$. Majority of the URTI and sinusitis were in the age range of 17 to 30 . From the case records it was evident that the reason for admission was recurrent infection rather than any other associated illness.

Prescription by brand name was more prevalent than the generic name. Prescribing by brand name may be resulted due to a large scale promotional activities done by pharmaceutical companies and this need to be discouraged. Prescribing by generic has few advantages like it aids the hospital pharmacy to have better inventory control and often generic medicines are more economic than the branded ones.

Only $40.7 \%$ of the drugs were prescribed from essential drug list. The low rate of prescribing of essential drugs is matter of concern. Excessive use of the multivitamins and combination preparation may be one of the factors 
responsible. The use of the bronchodilators, expectorants (mucolytic), antitussives which are not on the essential drug list may be another contributory factor.

Only in $18(8.49 \%)$ cases, the antimicrobial agents were not prescribed. Rest received antibiotics. Azithromycin was the most commonly used antimicrobial agent followed by ceftriaxone and cefixime. The benefits of antimicrobials are questionable as only few studies have found it to be beneficial.

In the study, antihistamines was found to be frequently used and the use of it is controversial as few studies suggests that it offers little support for common cold, while few studies supported the use of cold preparations to alleviate symptoms of sneezing and runny nose. ${ }^{15}$ Vitamin C, multivitamins and rare elements as zinc were prescribed even though no clear benefit or effectiveness was seen in multiple studies evaluating the ability of vitamin $\mathrm{C}$ to either prevent or to treat URTIs. ${ }^{5,16}$ Paracetamol is the preferred antipyretic used in the study. Acid reducing agents were prescribed in $82.54 \%$ of Patients, might be used to check the acidity caused by antibiotics

The average number of drugs used in non-specific URTI was 3.74 , the lower number of drugs noticed is welcome sign and need to be encouraged. There may be increase in compliance, lower cost of therapy and decreased risk of interaction when lesser number of drugs are used.

To conclude, it is observed from the present study that, URTI patients were commonly given antimicrobial agent and is a matter of concern. The most commonly used antibiotic was azithromycin followed by ceftriaxone. Apart from antibiotics the most frequently prescribed class was antihistamines followed by expectorants and bronchodilators. Paracetamol was the preferred antipyretic agent. Acid reducing agents were prescribed in $84.82 \%$ of patients, might be used to check the acidity caused by antibiotics. The use of generic medicines should be promoted.

\section{Funding: No funding sources}

Conflict of interest: None declared

Ethical approval: The study was approved by the Institutional Ethics Committee

\section{REFERENCES}

1. Ginde AA, Mansbach JM, Camargo CA. Association between serum 25-hydroxyvitamin D level and upper respiratory tract infection in the third national health and nutrition examination survey. Archives Internal Med. 2009;169(4):384-90.
2. Finch RG. Epidemiological features and chemotherapy of community-acquired respiratory tract infections. J Antimicrobial Chemo. 1990;26:53.

3. Hemming VG. Viral respiratory diseases in children: classification, etiology, epidemiology, and risk factors. J Pediatrics. 1994;124(5):13-6.

4. Manoharan A, Winter J. Tackling upper respiratory tract infections. Practitioner. 2010;254(1734):25-9.

5. Upper respiratory tract infections Cleveland. Available at http:// www. clevelandclinicmeded. com/medicalpubs/diseasemanagement/infectiousdisease/upper- respiratory- tract- infection/ Accessed on 1 August 2012.

6. Schroeder K, Fahey T. Over-the-counter medications for acute cough in children and adults in ambulatory settings. Cochrane Database Syst Rev. 2008;23(1):CD001831.

7. Foundation CMAC. Acute Respiratory Tract Infection Guideline Summary. Alliance Working for Antibiotic Resistance Education (AWARE). Available at https: //www.signup4.net/

Upload/KAIS13A/APRO281E/DeamerURTIsummaryf lyer2007.pdf. Accessed on 12 September 2015.

8. Arroll B, Smith GF. General practitioner management of upper respiratory tract infections: when are antibiotics prescribed? $\mathrm{N} \quad \mathrm{Z}$ Med J. 2000;113(1122):493-6.

9. Huang N, Chou YJ, Chang HJ, Ho M, Morlock L. Antibiotic prescribing by ambulatory care physicians for adults with nasopharyngitis, URIs, and acute bronchitis in Taiwan: a multi-level modeling approach. Family Practice. 2005;22(2):160-7.

10. Dagan R, Klugman KP, Craig WA, Baquero $\mathrm{F}$. Evidence to support the rationale that bacterial eradication in respiratory tract infection is an important aim of antimicrobial therapy. J Antimicrobial Chemothera. 2001;47(2):129-40.

11. Pradhan S, Shewade D, Shashindran C, Bapna J. Drug utilization studies. National Med J India. 1988;1:185-9.

12. Carroll K, Reimer L. Microbiology and laboratory diagnosis of upper respiratory tract infections. Clin Infect Dis. 1996;23(3):442-8.

13. Kaplan SL. The emergence of resistant pneumococcus as a pathogen in childhood upper respiratory tract infections. 1995;10(1):31-6.

14. Nandimath MK, Ahuja S. Drug prescribing pattern in upper respiratory tract infection in children aged 1-14 years. International Journal of Pharma and Bio Sciences. 2012;3(1):299-308.

15. Luks D, Anderson MR. Antihistamines and the common cold. J General Internal Med. 1996;11(4):2404.

16. Hemila H, Chalker E, Douglas B. Vitamin C for preventing and treating the common cold. Cochrane Database Syst Rev. 2007;3:CD000980.

Cite this article as: Naik H, Kolur A. Upper respiratory tract infection: drug utilization study. Int J Basic Clin Pharmacol 2016;5:1822-5. 